\title{
NATIONAL SCIENCE FOUNDATION
}

4201 WILSON BOULEVARD

ARLINGTON, VIRGINIA 22230

January 29, 2007

OFFICE OF THE

DEPUTY DIRECTOR

Ms. Alyson Reed

Executive Director

National Postdoctoral Association

1200 New York Avenue, NW., Suite 635

Washington, DC 20005

Dear Alyson:

We are pleased to inform you that the National Institutes of Health (NIH) and the National Science Foundation (NSF) have agreed upon the following definition of a postdoctoral scholar:

An individual who has received a doctoral degree (or equivalent) and is engaged in a temporary and defined period of mentored advanced training to enhance the professional skills and research independence needed to pursue his or her chosen career path.

The definition, which emphasizes the importance of mentored training during the postdoctoral period, will be used for all postdoctoral scholars supported by funding from NIH or NSF.

Thank you for the leadership that you and the National Postdoctoral Association provide as we work together to address issues critical for an effective postdoctoral appointment.

Sincerely,

Noke Reut Bowo

Norka Ruiz Bravo, Ph.D.

Deputy Director for Extramural Research

National Institutes of Health
Pathie Olans

Kathie L. Olsen, Ph.D.

Deputy Director

National Science Foundation 